\title{
A NOVEL METHODOLOGY FOR CHOOSING ACTUATORS OF CABLE-SUSPENDED PARALLEL ROBOTS *
}

\author{
UDC ((621.313.14:621.315.2):004.4PPACM)
}

\author{
Mirjana Filipović1 ${ }^{\text {, Ljubinko B. Kevac }}{ }^{2}$ \\ ${ }^{1}$ Mihajlo Pupin Institute, University of Belgrade, Serbia \\ ${ }^{2}$ School of Electrical Engineering, The University of Belgrade, Serbia
}

\begin{abstract}
A novel methodology for choosing actuators of a CPR system has been defined. This methodology is based on a novel procedure for analysis and synthesis of the workspace of Cable-suspended parallel robot, CPR system. Besides the kinematic and dynamic models of the CPR system, this procedure includes the complete mathematical model of the actuator as well. On this basis, this procedure presents a novel solution for the analysis and synthesis of a CPR system's workspace. When using the proposed methodology for choosing actuators of a CPR system, the user and designer together define the corresponding technical requirements, one of them being the relative size of the feasible work space of the CPR system. Based on these requirements, the developed methodology tests available actuators from its data base and extracts the useful ones for the predefined specific purpose. The purpose of this research is to interconnect theoretical contributions from the CPR system's modelling and needs of the user and designer during their practical implementation. For this purpose, a user friendly program package called PPACM has been generated. The program package PPACM and obtained results have been validated through the presentation of several case studies.
\end{abstract}

Key words: cable robot, actuator choosing, workspace analysis and synthesis

Received July 3, 2018

Corresponding author: Mirjana Filipović

Mihajlo Pupin Institute, University of Belgrade, Volgina 15, 11060 Belgrade, Republic of Serbia

E-mail: dragan.zivanovic@elfak.ni.ac.rs

*Acknowledgement: This research has been supported by the Ministry of Education, Science and Technological Development, Government of the Republic of Serbia Grant TR-35003 through the following two projects: "Ambientally intelligent service robots of anthropomorphic characteristics", by Mihailo Pupin Institute, University of Belgrade, Serbia, Grant OI-174001 and "The dynamics of hybrid systems of complex structure", by Institute SANU Belgrade and Faculty of Mechanical Engineering University of Nis, Serbia.

We are grateful to Prof. Dr Katica R. (Stevanovic) Hedrih from Mathematical Institute, Belgrade for helpful consultations during the implementation of this paper. 


\section{INTRODUCTION}

Engineers and researchers started working on Cable-suspended parallel robots, CPR systems, during late 1980s and early 1990s. The first concepts of these systems appeared in the United States and Japan (cranes, parallel manipulators, cable-driven robotic systems). These systems became popular in time and are now making a constituent part of today's robotics. Some of the first cable driven systems, constructed few decades ago, were NIST robo - crane [1] and FALCON (Fast Load Conveyance) robot [2].

In our previous research [3]-[5], we dealt with the analysis, synthesis, and mathematical modelling of different types of CPR systems.

Besides all other aspects, one of important subjects in considering a CPR system is the analysis and synthesis of its workspace. It was a topic of interest of many authors since the first CPR systems were analyzed and synthesized. Several papers which deal with this problem will be cited in this paper. In [6], the authors studied the design and workspace of a 6-6 cable-suspended parallel robot. The workspace volume is characterized as the set of points where the centroid of the moving platform can reach, with tensions in all suspension cables, at a constant orientation. Paper [7] is focused on the workspace analysis of fully restrained positioning mechanisms. Because the cable tension is the essential issue concerning the constraints of a moving platform, the forceclosure workspace was mainly studied. In [8], the authors presented a workspace analysis of a 4-cable driven parallel manipulator by using the interval analysis. A prototype has been built and the tests demonstrated the feasibility of the cable system design and its operation for planar and spatial tasks. In [9] the authors used the convex set theory for solving the force-closure workspace. In [10] two typical types of workspace, namely force-closure workspace and feasible-wrench workspace, for fully restrained cable-driven parallel manipulators were addressed through the corresponding tension conditions. Implementing recursive algorithms in checking the tension conditions was found straightforward and efficient. In [11] a cable-based parallel structure for rehabilitation of the movements of the human shoulder named CaMaReS (Cable Manipulator for Rehabilitation of Shoulder) is presented. The robotic structure consisted of four cables that allowed the shoulder movements with different limits of the movement and speed. After kinematics modelling, the kinds of workspace were defined and then a statically reachable combined workspace for different geometric structures of fixed and/or moving platform was obtained. In [12], springs were added between the end effector and the base with the goal of modulating the workspace. The effects of different parameters of the spring on CDPR's wrenches were investigated and an optimization was proposed to determine the feasible spring parameters. The work reported in [13] is focused on the workspace analysis and verification of a redundant constraint of a 6-DOF cable-driven parallel suspension system. Based on the system motion and dynamics equations, the geometrical interference (either intersection between two cables or between a cable and the aircraft) and cable tension restraint conditions were constructed and analyzed. In [14], a workspace analysis was carried out for a wrench-feasible condition in a 6-DOF CDPR system considering the pulley bearing friction connected in series. The kinematics and dynamics of the CDPR system were derived through vector equations and D'Alembert's principle.

This paper is based on the analysis and synthesis of the CPR system's workspace as well. And based on conclusions from this analysis and synthesis, a novel methodology 
for choosing the actuators of a CPR system was developed. The papers which inspired the research reported in this paper are [15] - [17]. In [15], the authors introduced a new tool, the so called Twist Feasible Workspace (TFW), developed in order to analyze the workspace of platform twists. A pose was said to be twist feasible if the platform of a CDPR could assume a given range of linear and rotational velocities, while satisfying the cable speed limitations imposed by the actuators and transmission systems. The size of a TFW was used as an optimization criterion for dimensioning of the actuators and winches. In [16], a scenario-based method for dimensioning the actuator of the cable robot's winch was presented. For arbitrary robot geometries and application requirements the load spectra for the actuator unit can be easily generated. The generated data allow to exhaust the overload potential of the drives. This workflow leads to the well dimensioned drives. Furthermore, an optimization approach for the trajectory time for a given drive unit is shown. It deals with the compromise between the guaranteed acceptable cable forces and the maximum dynamic. In [15] and [16], and in the previously mentioned papers, the analysis and synthesis of the workspace was based on the kinematic and partly on dynamic level. The analyses on dynamic level presented in [6]-[16] did not include the impact of parameters of actuators on CPR system's workspace. Inspired by the previously published papers, a novel procedure for the analysis and synthesis of CPR system's workspace is developed in this paper. This procedure includes, besides CPR system's kinematics and dynamics, the parameters of actuators and their influence on CPR system's workspace. This procedure is named CPR-WWA (CPR-Whole Workspace Analysis).

The defined procedure gave us the opportunity to formulate a novel methodology for choosing the CPR system's actuator. An actuator is composed from the motor, gearbox, and a winch. The novel methodology was named CPR-ACM (CPR- $\underline{A}$ ctuator $\underline{\text { Choice }}$ Methodology). This methodology is dependent on a number of the CPR system's parameters, such as: configuration of the system, its dimensions, weight of the load, load's velocity, type of the winch and its winding/unwinding radius, gearbox characteristics, and especially characteristics of the motor. Choosing the actuator of a CPR system is presented through a flow chart. The whole methodology was defined and tested by using the program package PPACM (Program Package Actuator Choice Methodology). In this paper, methodology CPR-ACM was tested on a chosen configuration of a CPR system named the CPR-8 system, but it can be tested on any robotic configuration.

The paper is divided as follows: after Introduction, Section 2 presents a redundant CPR system named the CPR-8 and its mathematical model. After, in Section 3, a procedure CPR-WWA used for the analysis and synthesis of the CPR-8 system's workspace is described. In Section 4, a novel methodology for making choice of CPR-8 system's actuator, named CPR-ACM, is shown. In Section 5, program package PPACM was presented and tested. The paper is ended by a Conclusion.

\section{REDUNDANT CPR SYSTEM: CPR-8}

A CPR system which carries system load (or a tool) via eight ropes is described. Each rope is controlled by an actuator, which means that this CPR system contains 8 actuators. Motion of the load is in 6DOF of the Cartesian space, which means that this CPR system is redundant. The system, named CPR-8 system, is presented in Fig. 1. 
The position and orientation of the center of mass of the load carrier is defined by

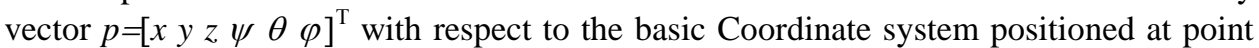
$O$, see Fig. 1. Workspace of CPR-8 system is of a shape of parallelepiped of dimensions $d \cdot s \cdot v$, and load carrier presents a scaled parallelepiped of dimensions $l \cdot w \cdot h_{o}=$ $n_{s} \cdot(d \cdot s \cdot v)$, where $n_{s}$ presents a scaling factor. The upper vertices of the load carrier are defined by points $A, B, C, D$, while its lower vertices are defined by points $A^{\prime}, B^{\prime}, C^{\prime}, D^{\prime}$, see Fig. 1.

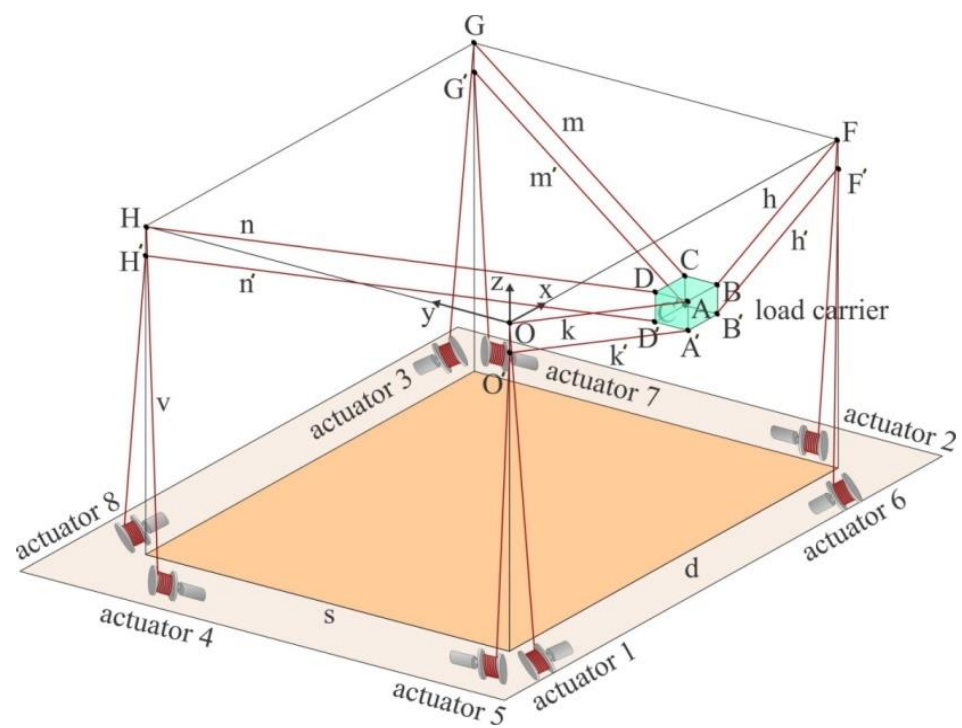

Fig. 1 CPR-8 system in 3D space

Each vertex is connected by the corresponding rope. Upper vertices of the carrier $A$, $B, C, D$ are connected with upper vertices of the workspace $O, F, G, H$ (upper hanging points) and then with the winches of actuators 1, 2, 3, 4, respectively. Analogously, the lower vertices of the carrier are connected with points $O^{\prime}, F^{\prime}, G^{\prime}, H^{\prime}$ (lower hanging points) and then with the winches of actuators 5, 6, 7, 8, respectively. Points $O^{\prime}, F, G$, $H^{\prime}$ are at a distance $h_{o}$ from points $O, F, G, H$ in the vertical axis. Distances between vertices of the load carrier and the corresponding hanging points in the workspace are defined as: $k=\underline{A O}, h=\underline{B F}, m=\underline{C}, n=\underline{D H}, k^{\prime}=\underline{A^{\prime}}, h^{\prime}=\underline{B^{\prime}} F^{\prime}, m^{\prime}=C^{\prime} G^{\prime}, n^{\prime}=\underline{D^{\prime} H^{\prime}}$. These distances are variable during the implementation of the CPR-8 system's task and they are very important for definition of the kinematic and dynamics models of the CPR-8 system.

It was constructively provided that lengths between the hanging points $O, F, G, H, O$, $F^{\prime}, G^{\prime}, H^{\prime}$ and the corresponding actuators $1,2,3,4,5,6,7,8$ respectively, are constant. This means that these lengths are not included in the kinematic and dynamic equations, unlike in [18] and [19] where these lengths are variable.

The position and orientation of the load carrier's center of mass $p$ is named: vector of outer coordinates. It is assumed that the rotation of actuator's shaft behind the gearbox is defined by a vector: $\phi=\left[\theta_{1} \theta_{2} \theta_{3} \theta_{4} \theta_{5} \theta_{6} \theta_{7} \theta_{8}\right]^{T}$ and these variables are named: inner coordinates. 
The position of carrier's center of mass is defined in the Cartesian space as $T=[x y z]^{T}$. If each carrier's vertex is defined in the Cartesian space, it can be written:

$$
\begin{gathered}
{\left[\mathrm{x}_{\mathrm{A}} \mathrm{y}_{\mathrm{A}} \mathrm{z}_{\mathrm{A}}\right]^{\mathrm{T}}=\mathrm{T}+\mathrm{R} \times\left[-\frac{1}{2}-\frac{\mathrm{w}}{2}+\frac{\mathrm{h}_{\mathrm{o}}}{2}\right]^{\mathrm{T}},} \\
{\left[\mathrm{x}_{\mathrm{B}} \mathrm{y}_{\mathrm{B}} \mathrm{z}_{\mathrm{B}}\right]^{\mathrm{T}}=\mathrm{T}+\mathrm{R} \times\left[+\frac{1}{2}-\frac{\mathrm{w}}{2}+\frac{\mathrm{h}}{2}\right]_{\mathrm{o}}^{\mathrm{T}},} \\
{\left[\mathrm{x}_{\mathrm{C}} \mathrm{y}_{\mathrm{C}} \mathrm{z}_{\mathrm{C}}\right]^{\mathrm{T}}=\mathrm{T}+\mathrm{R} \cdot\left[+\frac{1}{2}+\frac{\mathrm{w}}{2}+\frac{\mathrm{h}_{\mathrm{o}}}{2}\right]^{\mathrm{T}},} \\
{\left[\mathrm{x}_{\mathrm{D}} \mathrm{y}_{\mathrm{D}} \mathrm{z}_{\mathrm{D}}\right]^{\mathrm{T}}=\mathrm{T}+\mathrm{R} \cdot\left[-\frac{1}{2}+\frac{\mathrm{w}}{2}+\frac{\mathrm{h}_{\mathrm{o}}}{2}\right]^{\mathrm{T}},} \\
{\left[\mathrm{x}_{\mathrm{A}^{\prime}} \mathrm{y}_{\mathrm{A}^{\prime}} \mathrm{z}_{\mathrm{A}^{\prime}}\right]^{\mathrm{T}}=\mathrm{T}+\mathrm{R} \cdot\left[-\frac{1}{2}-\frac{\mathrm{w}}{2}-\frac{\mathrm{h}_{\mathrm{o}}}{2}\right]^{\mathrm{T}},} \\
{\left[\mathrm{x}_{\mathrm{B}^{\prime}} \mathrm{y}_{\mathrm{B}^{\prime}} \mathrm{z}_{\mathrm{B}^{\prime}}\right]^{\mathrm{T}}=\mathrm{T}+\mathrm{R} \cdot\left[+\frac{1}{2}-\frac{\mathrm{w}}{2}-\frac{\mathrm{h}_{\mathrm{o}}}{2}\right]^{\mathrm{T}},} \\
{\left[\mathrm{x}_{\mathrm{D}^{\prime}} \mathrm{y}_{\mathrm{D}^{\prime}} \mathrm{z}_{\mathrm{D}^{\prime}}\right]^{\mathrm{T}}=\mathrm{T}+\mathrm{R} \cdot\left[-\frac{1}{2}+\frac{\mathrm{w}}{2}-\frac{\mathrm{h}_{\mathrm{o}}}{2}\right]^{\mathrm{T}},} \\
{\left[\mathrm{x}_{\mathrm{C}^{\prime}} \mathrm{y}_{\mathrm{C}^{\prime}} \mathrm{z}_{\mathrm{C}^{\prime}}\right]^{\mathrm{T}}=\mathrm{T}+\mathrm{R} \cdot\left[+\frac{\mathrm{w}}{2}+\frac{\mathrm{w}}{2}-\frac{\mathrm{h}}{2}\right]^{\mathrm{T}},}
\end{gathered}
$$

Rotation matrix $R$ which is present in equations (1)-(8) is defined as:

$$
\mathrm{R}=\left[\begin{array}{ccc}
\mathrm{c} \varphi \cdot \mathrm{c} \theta & \mathrm{c} \varphi \cdot \mathrm{s} \theta \cdot \mathrm{s} \psi-\mathrm{s} \varphi \cdot \mathrm{c} \psi & \mathrm{c} \varphi \cdot \mathrm{s} \theta \cdot \mathrm{c} \psi+\mathrm{s} \varphi \cdot \mathrm{s} \psi \\
\mathrm{s} \varphi \cdot \mathrm{c} \theta & \mathrm{s} \varphi \cdot \mathrm{s} \theta \cdot \mathrm{s} \psi+\mathrm{c} \varphi \cdot \mathrm{c} \psi & \mathrm{s} \varphi \cdot \mathrm{s} \theta \cdot \mathrm{s} \psi-\mathrm{c} \varphi \cdot \mathrm{c} \psi \\
-\mathrm{s} \theta & \mathrm{c} \theta \cdot \mathrm{s} \psi & \mathrm{c} \theta \cdot \mathrm{c} \psi
\end{array}\right]
$$

Instead of using $\cos$ and $\sin$, abbreviations $c$ and $s$ were used, respectively. In the following step, variables $k, h, m, n, k^{\prime}, h^{\prime}, m^{\prime}, n^{\prime}$ are defined:

$$
\begin{gathered}
\mathrm{k}=\sqrt{\mathrm{x}_{\mathrm{A}}{ }^{2}+\mathrm{y}_{\mathrm{A}}{ }^{2}+\mathrm{z}_{\mathrm{A}}{ }^{2}}, \\
\mathrm{~h}=\sqrt{\left(\mathrm{d}-\mathrm{x}_{\mathrm{B}}\right)^{2}+\mathrm{y}_{\mathrm{B}}{ }^{2}+\mathrm{z}_{\mathrm{B}}{ }^{2}}, \\
\mathrm{~m}=\sqrt{\left(\mathrm{d}-\mathrm{x}_{\mathrm{C}}\right)^{2}+\left(\mathrm{s}-\mathrm{y}_{\mathrm{C}}\right)^{2}+\mathrm{z}_{\mathrm{C}}{ }^{2}},
\end{gathered}
$$




$$
\begin{gathered}
\mathrm{n}=\sqrt{\mathrm{x}_{\mathrm{D}}{ }^{2}+\left(\mathrm{s}-\mathrm{y}_{\mathrm{D}}\right)^{2}+\mathrm{z}_{\mathrm{D}}{ }^{2}}, \\
\mathrm{k}^{\prime}=\sqrt{\mathrm{x}_{\mathrm{A}^{\prime}}{ }^{2}+\mathrm{y}_{\mathrm{A}^{\prime}}{ }^{2}+\left(\mathrm{h}_{\mathrm{o}}+\mathrm{z}_{\mathrm{A}^{\mathrm{A}^{\prime}}}\right)^{2}}, \\
\mathrm{~h}^{\prime}=\sqrt{\left(\mathrm{d}-\mathrm{x}_{\mathrm{B}^{\prime}}\right)^{2}+\mathrm{y}_{\mathrm{B}^{\prime}}{ }^{2}+\left(\mathrm{h}_{\mathrm{o}}+\mathrm{z}_{\mathrm{B}^{\prime}}\right)^{2}}, \\
\mathrm{n}^{\prime}=\sqrt{\left.\mathrm{x}_{\mathrm{D}^{\prime}}{ }^{2}+\left(\mathrm{s}-\mathrm{x}_{\mathrm{C}^{\prime}}\right)^{2}+\left(\mathrm{s}-\mathrm{y}_{\mathrm{C}^{\prime}}\right)^{\prime}\right)^{2}+\left(\mathrm{h}_{\mathrm{o}}+\mathrm{z}_{\mathrm{C}^{\prime}}\right)^{2}},
\end{gathered}
$$

To make a geometric relation between the outer and inner coordinates the relation between variables $\dot{k}, \dot{h}, \dot{m}, \dot{n}, \dot{\mathrm{k}}^{\prime}, \dot{\mathrm{h}}^{\prime}, \dot{\mathrm{m}}^{\prime}, \dot{\mathrm{n}}^{\prime}$, and actuators' shafts' rotation velocity needs to be defined first:

$$
\dot{\theta}_{1}=\frac{\dot{\mathrm{k}}}{\mathrm{R}_{1}}, \dot{\theta}_{2}=\frac{\dot{\mathrm{h}}}{\mathrm{R}_{2}}, \dot{\theta}_{3}=\frac{\dot{\mathrm{m}}}{\mathrm{R}_{3}}, \dot{\theta}_{4}=\frac{\dot{\mathrm{n}}}{\mathrm{R}_{4}}, \dot{\theta}_{5}=\frac{\dot{\mathrm{k}}^{\prime}}{\mathrm{R}_{5}}, \dot{\theta}_{6}=\frac{\dot{\mathrm{h}}^{\prime}}{\mathrm{R}_{6}}, \dot{\theta}_{7}=\frac{\dot{\mathrm{m}}^{\prime}}{\mathrm{R}_{7}}, \dot{\theta}_{8}=\frac{\dot{\mathrm{n}}^{\prime}}{\mathrm{R}_{8}} .
$$

Winding/unwinding radii of winches $R_{i}(i=1, \ldots, 8)$ participate in eqs. (18). Now, if first derivatives of variables defined in eqs. (10)-(17) are made and substituted in eqs. (18), a relation between the first derivatives of shafts' rotary motion $\dot{\phi}=\left[\begin{array}{llllllll}\dot{\theta}_{1} & \dot{\theta}_{2} & \dot{\theta}_{3} & \dot{\theta}_{4} & \dot{\theta}_{5} & \dot{\theta}_{6} & \dot{\theta}_{7} & \dot{\theta}_{8}\end{array}\right]^{\mathrm{T}}$ and first derivatives of load carrier's motion

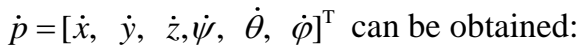

$$
\dot{\phi}=\mathrm{J}_{8 \times 6} \cdot \dot{\mathrm{p}} .
$$

Eq. (19) presents a kinematic model of the CPR-8 system from Fig. 1. The kinematic model is defined by the Jacobian matrix $J$. This matrix is a full matrix, because of the strong coupling between the variables from the outer and inner spaces of the CPR-8 system.

It is required to establish a relation between the outer forces and torques which act at the load carrier $F=\left[F_{x} F_{y} F_{z} M_{z} M_{y} M_{x}\right]^{\mathrm{T}}$ and torques which act at actuators' shafts behind

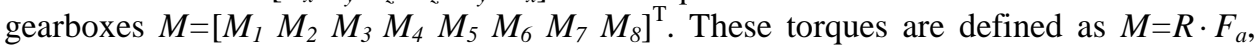
where $F_{a}$ represents the vector of tension forces in the corresponding cable, $F_{a}=\left[F_{k} F_{h} F_{m}\right.$ $\left.F_{n} F_{k}, F_{h}, F_{m}, F_{n}\right]^{\mathrm{T}}$, while $R$ represents matrix $R=\operatorname{diag}\left(R_{i}\right)$. Based on the results from [4] where the Lagrange principle of virtual work was defined, the relation between vectors $F$ and $M$ can be written as:

$$
\mathrm{M}=\left(\mathrm{J}^{\mathrm{T}}\right)^{\dagger} \cdot \mathrm{F},
$$

where $\left(\mathrm{J}^{\mathrm{T}}\right)^{\dagger}$ represents Moore-Penrose pseudo-inverse of matrix $\mathrm{J}^{T}$ Eq. (20) belongs to the dynamic model of the CPR- 8 system, but it is not sufficient for defining the complete dynamic model of the CPR-8 system. The complete dynamic model also includes mathematical model of the actuator with all its parameters: 


$$
\mathrm{u}=\mathrm{G}_{\mathrm{v}} \cdot \ddot{\phi}+\mathrm{L}_{\mathrm{v}} \cdot \dot{\phi}+\mathrm{S}_{\mathrm{v}} \cdot \mathrm{M},
$$

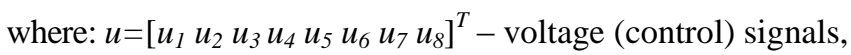

$G_{v}=\operatorname{diag}\left(G_{v i}\right)-$ motor inertia characteristic,

$L_{v}=\operatorname{diag}\left(L_{v i}\right)-$ motor damping characteristic,

$S_{v}=\operatorname{diag}\left(S_{v i}\right)-$ motor geometric characteristic.

The kinematic and dynamic models of the CPR-8 system are defined by eqs. (19) and (21), respectively. In the next Section, the procedure for analysis and synthesis of the CPR-8 system's workspace will be defined.

\section{THE PROCEDURE FOR ANALYSIS AND SYNTHESIS OF CPR SYSTEM'S WORKSPACE: CPR-WWA}

The pioneering investigations of the CPR system's workspace which can be found in the literature were based only on its geometry. Later, the authors of many papers [6]-[16] have analyzed the influence of external forces and torques on the size of CPR system's workspace.

Unlike the work published so far, it was noticed in this work that the whole dynamics of the CPR system as well as the dynamics of its actuators have influence on the size of feasible workspace. These results will be presented in this section and further through the paper. Also, in order to facilitate understanding, only effects presumed in this paper will be presented.

If it is presumed that the load carrier is described as a dimensionless mass, i.e. a point, which is carried by eight ropes, then the theoretical workspace of the CPR-8 system has a shape of the parallelepiped $d \cdot s \cdot v$, see Fig. 2.

However, in reality the load carrier always has a geometric shape. This shape reduces the theoretical workspace of the system [8]. In the case presented in this paper, the load carrier has a shape of a parallelepiped $l \cdot w \cdot h_{o}$. In that case, dimensions of the load carrier reduce the theoretical workspace from all sides by the value $d_{c}=\sqrt{(1 / 2)^{2}+(w / 2)^{2}+\left(h_{o} / 2\right)^{2}}$, which presents one half of the main diagonal of the carrier. This is the worst-case, when orientation of the carrier is such that the carrier's center of mass is at distance $d_{e}$ from the borders of the theoretical workspace. The reduced geometric workspace of the CPR-8 system, shown in Fig. 3, has the following dimensions $\left(d-2 d_{e}\right) \cdot\left(s-2 d_{e}\right) \cdot\left(v-2 d_{e}\right)$.

The workspaces presented in Figs. 2 and 3 do not consider dynamic parameters of the CPR-8 system. In order to acquire the feasible workspace of the CPR-8 system, it is necessary that its dynamic parameters are included in the analysis as well. The dynamic parameters are parameters of the actuators, workspace geometry, load carrier geometry, desired velocity of the system, load weight, etc. These will be included in the procedure to be presented.

The Lagrange principle of virtual work, given by eq. (20) and kinematic eq. (19), is included in the analysis and synthesis of the CPR-8 system's workspace. Besides these equations, actuator equation (21) is also included. It is one of the novelties of this paper in comparison with the previously published work. Based on these principles a novel procedure for analysis and synthesis of CPR-8 system's workspace CPR-WWA is defined and will be presented in this Section. 


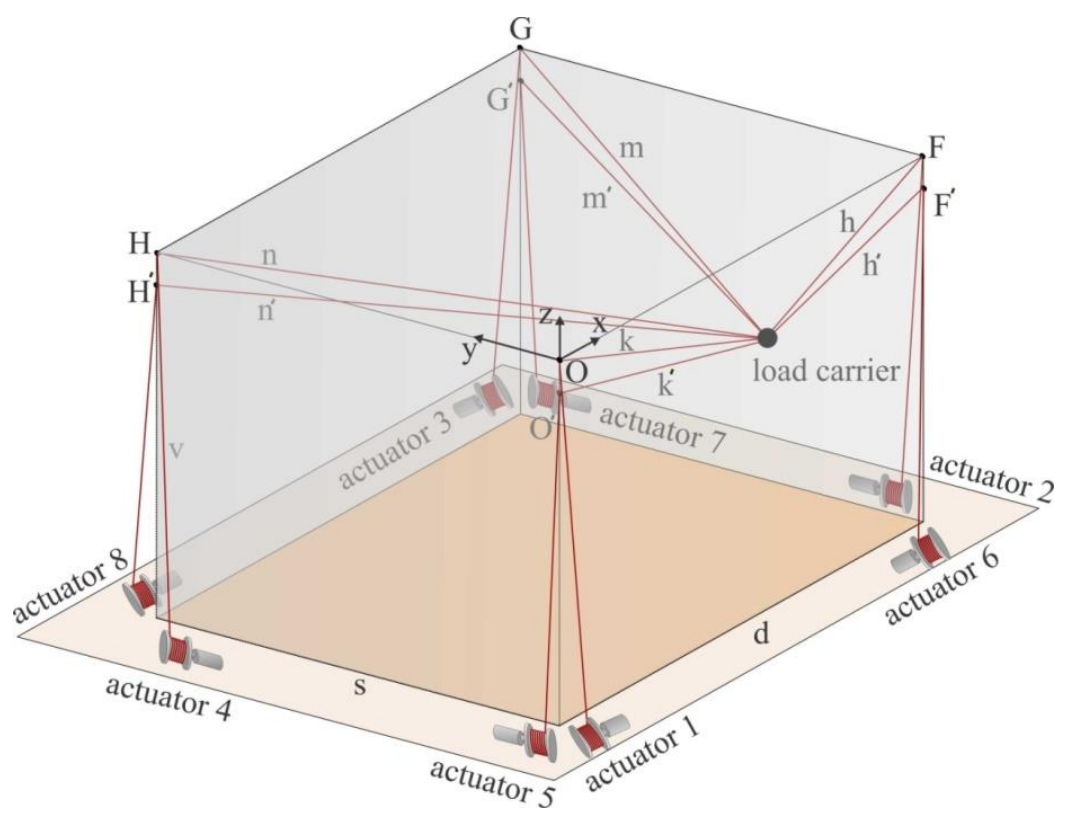

Fig. 2 Theoretical workspace of the CPR-8 system

Components of the CPR system dictate the corresponding set of constraints. Some of them are set by the user's requirements: dimensions of the workspace, load carrier's velocity, etc.; while some of them are set by the CPR system's design: load weight, winches radii; and the rest of them are set by the components which are available at the market: motors, gearboxes, etc. It is clear that all of these components need to be mutually compatible and adequately designed to make the system function as it is required by the corresponding technical requirements.

For CPR-8 system's functioning, the choice of a good actuator is very important. To check if the actuator satisfies all specified technical requirements, its catalogue parameters are used. The important catalogue parameters of five actuators are given in Table. 1.

In order to use catalogue parameters, several actuator characteristics need to be defined. E.g. torque transmission ratio is $N_{M i}=N_{V i} \cdot \xi_{i}$. It should be noticed that catalogue values are usually not given in SI units, so they need to be harmonized with the rest of variables from eq. (21) first. Next, the following variables are defined: $C_{E i}=C_{e i} \cdot N_{V i}$, $C_{M i}=C_{m i} \cdot N_{M i}, B_{C i}=B_{c i} \cdot N_{V i} \cdot N_{M i}, J_{r i}=J_{M i} \cdot N_{V i} \cdot N_{M i}$. Only then, the variables which characterize eq. (21) can be written:

$$
\mathrm{G}_{\mathrm{vi}}=\frac{\mathrm{J}_{\mathrm{ri}} \cdot \mathrm{R}_{\mathrm{ri}}}{\mathrm{C}_{\mathrm{Mi}}}, \mathrm{L}_{\mathrm{vi}}=\frac{\mathrm{B}_{\mathrm{Ci}} \cdot \mathrm{R}_{\mathrm{ri}}}{\mathrm{C}_{\mathrm{Mi}}}+\mathrm{C}_{\mathrm{Ei}} \text { and } \mathrm{S}_{\mathrm{vi}}=\frac{\mathrm{R}_{\mathrm{ri}}}{\mathrm{C}_{\mathrm{Mi}}} .
$$

In Table 1 , an appropriate winch was defined, i.e. its radius $R_{i}$, which can significantly affect the size of the feasible workspace.

Because it would be impossible to analyze every point of the geometric workspace, it was divided in $N \cdot N \cdot N$ points in the Cartesian workspace along $x, y$ and, $z$ directions. 
It means that for the CPR-WWA procedure, the interval workspace analysis is chosen. The following constraints are defined for each point:

1) The constraints for the load carrier velocity are introduced as $v_{c} \leq V_{c \max }$. The algorithm assumes a trapezoidal shape of velocity $v_{c}$ with precisely defined acceleration $t_{\text {acc }}$ and deceleration $t_{\text {dec }}$ times.

2) Load weight $m$ is defined by the design and task requirements.

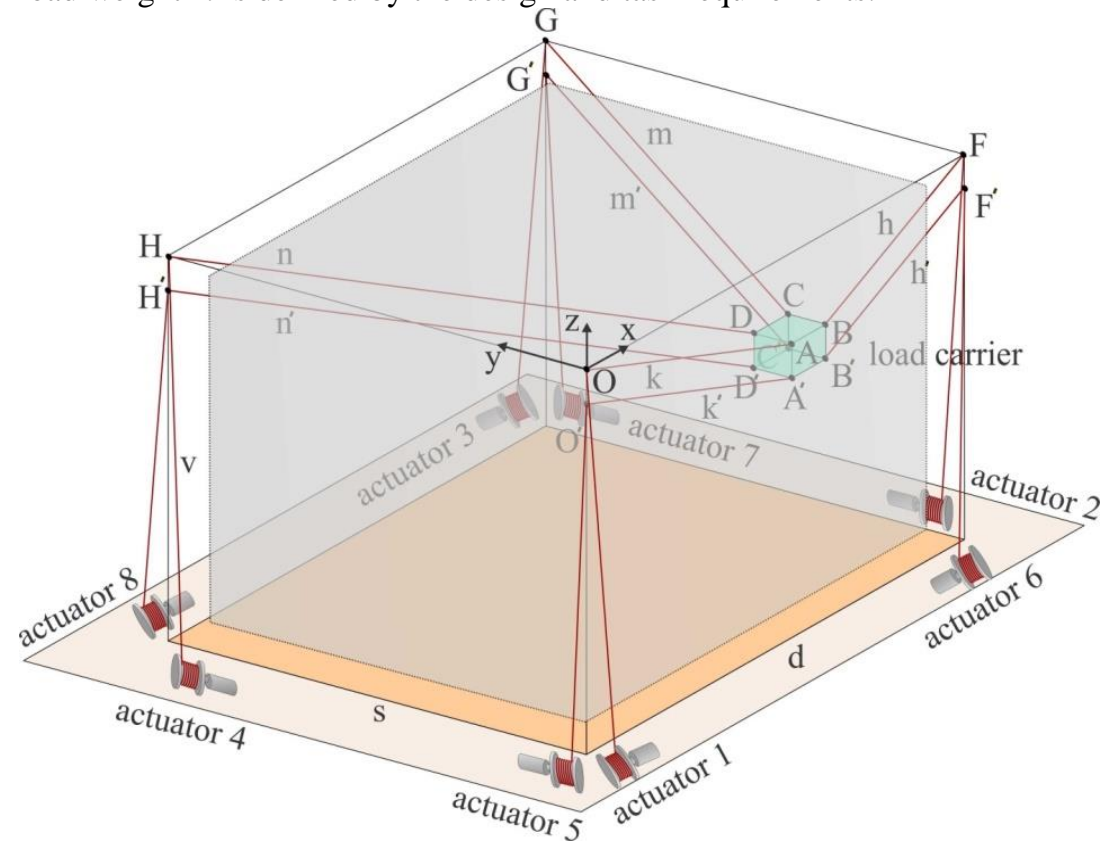

Fig. 3 Geometric workspace of the CPR-8 system

Based on constraint 1), the following variables are calculated in the defined intervals:

$$
\begin{aligned}
& \dot{\mathrm{x}}=\left\{-\mathrm{V}_{\mathrm{c} \max }: \frac{2 \cdot \mathrm{V}_{\mathrm{c} \text { max }}}{\mathrm{N}}:+\mathrm{V}_{\mathrm{c} \max }\right\}, \\
& \dot{\mathrm{y}}=\left\{-\mathrm{V}_{\mathrm{c} \max }: \frac{2 \cdot \mathrm{V}_{\mathrm{c} \text { max }}}{\mathrm{N}}:+\mathrm{V}_{\mathrm{c} \max }\right\}, \\
& \dot{\mathrm{z}}=\left\{-\mathrm{V}_{\mathrm{c} \max }: \frac{2 \cdot \mathrm{V}_{\mathrm{c} \max }}{\mathrm{N}}:+\mathrm{V}_{\mathrm{c} \max }\right\},
\end{aligned}
$$

with the following condition which needs to be satisfied at each tested point in the workspace, i.e. for any tested combination $k$ :

$$
\mathrm{v}_{\mathrm{c}}(\mathrm{k}) \leq \mathrm{V}_{\mathrm{c} \max }
$$

where $\mathrm{v}_{\mathrm{c}}(\mathrm{k})=\sqrt{(\dot{\mathrm{x}}(\mathrm{k}))^{2}+(\dot{\mathrm{y}}(\mathrm{k}))^{2}+(\dot{\mathrm{z}}(\mathrm{k}))^{2}}$. 
Table 1 Actuator parameters

\begin{tabular}{lccccc}
\hline Actuator & 1 & 2 & 3 & 4 & 5 \\
\hline Output power $\mathrm{P}_{\text {mot }}[\mathrm{W}]$ & 300 & 100 & 50 & 20 & 10 \\
Voltage $\mathrm{U}_{\text {mot }}[\mathrm{V}]$ & 48 & 48 & 24 & 24 & 18 \\
Speed $\omega_{\text {mot }}[\mathrm{RPM}]$ & 4700 & 3970 & 4500 & 5060 & 4777 \\
Torque $\mathrm{M}_{\text {mot }}[\mathrm{Nm}]$ & 0.6 & 0.319 & 0.131 & 0.212 & 0.03 \\
Back-EMF constant $\mathrm{C}_{\mathrm{ei}}[\mathrm{V} /(\mathrm{rad} / \mathrm{s})]$ & 0.0945 & 0.1145 & 0.0356 & 0.0352 & 0.029 \\
Torque constant $\mathrm{C}_{\mathrm{mi}}[\mathrm{Nm} / \mathrm{A}]$ & 0.095 & 0.114 & 0.0357 & 0.0352 & 0.0299 \\
Viscous friction $\mathrm{B}_{\mathrm{ci}}[\mathrm{Nm} /(\mathrm{rad} / \mathrm{s})]$ & 0 & 0 & 0 & 0 & 0 \\
Rotor circuit resistance $\mathrm{R}_{\mathrm{ri}}[\Omega]$ & 0.369 & 1.1 & 0.567 & 3.99 & 3.01 \\
Actuator inertia $\mathrm{J}_{\mathrm{Mi}}\left[\mathrm{gcm}^{2}\right]$ & 3579 & 1210 & 181 & 45.3 & 9.26 \\
Gear ratio $\mathrm{N}_{\mathrm{Vi}}$ & 30 & 25 & 26 & 30 & 26 \\
Actuator efficiency coefficient & 0.6 & 0.7 & 0.7 & 0.7 & 0.7 \\
Winch radius $\mathrm{R}_{\mathrm{i}}[\mathrm{m}]$ & 0.08 & 0.08 & 0.08 & 0.08 & 0.08 \\
\hline
\end{tabular}

Then, the constraints for the second derivatives of the Cartesian coordinates are written:

$$
\begin{aligned}
& \ddot{x}=\left\{\frac{-V_{c \max }}{t_{d e c}}: \frac{+V_{c \max }}{t_{a c c}}\right\}, \\
& \ddot{y}=\left\{\frac{-V_{c \max }}{t_{d e c}}: \frac{+V_{c \max }}{t_{a c c}}\right\}, \\
& \ddot{z}=\left\{\frac{-V_{c \max }}{t_{d e c}}: \frac{+V_{c \max }}{t_{a c c}}\right\} .
\end{aligned}
$$

For orientation of the load carrier, it was assumed that Euler angles $\psi, \theta$ and $\varphi$ have constant values. That means that their first derivatives are zero.

Based on the so far assumed constraints, by using eq. (19), vector $\dot{\phi}$ can be calculated. Through this vector, the first workspace test can be conducted, because the motor speed has a catalogue defined limit. The condition is as follows:

$$
\left|\dot{\theta}_{\mathrm{i}}(\mathrm{k})\right| \leq \frac{\omega_{\mathrm{mot}}}{9.5493 \cdot \mathrm{N}_{\mathrm{vi}}} .
$$

By looking at eq. (21), it can be seen that the constraints also need to be defined for vectors $M, u$, and $\ddot{\phi}$.

With constraint 2) the load weight was defined, so the vector of outer forces and torques $F$ can be defined as:

$$
F(k)=\left[\begin{array}{llllll}
m \cdot \ddot{x}(k) & m \cdot \ddot{y}(k) & m \cdot(\ddot{z}(k)-g) & 0 & 0 & 0
\end{array}\right]^{T},
$$


where $g$ represents gravitational acceleration. From eq. (31), it can be seen that the torques around axes $x, y$, and $z$ are zero, because of the assumption that Euler angles have constant values.

By using eq. (20), vector torques, $M$, can be calculated. The torque which acts at each actuator's shaft needs to satisfy the following condition, defined by its catalogue parameters:

$$
\left|M_{i}(k)\right| \leq M_{m o t} \cdot N_{M i}
$$

Then, vector $\ddot{\phi}$ needs to be constrained. These constraints were defined by the following equation:

$$
\left|\ddot{\theta}_{\mathrm{i}}\right|=\left\{\frac{-\mathrm{M}_{\mathrm{mot}} \cdot \mathrm{N}_{\mathrm{Mi}}}{\mathrm{J}_{\mathrm{ri}}}: \frac{+\mathrm{M}_{\mathrm{mot}} \cdot \mathrm{N}_{\mathrm{Mi}}}{\mathrm{J}_{\mathrm{ri}}}\right\} .
$$

Based on eq. (21), the control signals can be calculated for each $k$-th combination. The control signals need to be constrained according to catalogue parameters of the chosen actuator:

$$
\left|\mathrm{u}_{\mathrm{i}}(\mathrm{k})\right| \leq \mathrm{U}_{\mathrm{mot}} \cdot
$$

In this fashion, all the variables are constrained according to the catalogue parameters of the chosen actuator: motor + gearbox + winch. By using eqs. (23)-(34), a novel procedure CPR-WWA for the analysis and synthesis of the CPR-8 system's workspace is defined. By its application, a feasible workspace of the CPR-8 system can be calculated. In the following part of this Section, a comparative analysis of the results achieved with the CPR-WWA procedure and the corresponding simulation experiments will be shown.

\subsection{A case study}

The analysis and synthesis of a feasible workspace were made for a CPR-8 system of dimensions $d \cdot s \cdot v=3,2[\mathrm{~m}] \cdot 2,2[\mathrm{~m}] \cdot 2,2[\mathrm{~m}]$. Load weight is $m=2[\mathrm{~kg}]$, while dimensions of the load carrier are $l \cdot w \cdot h_{o}=0,224[\mathrm{~m}] \cdot 0,154[\mathrm{~m}] \cdot 0,140[\mathrm{~m}]$. Maximal value of the reference velocity is $V_{c \max }=1,3[\mathrm{~m} / \mathrm{s}]$, while the acceleration and deceleration times are $t_{a c c}=t_{d e c}=1,82[\mathrm{~s}]$. It was assumed that the actuator of the same type was used for all eight ropes. This case study was implemented by using Actuator 1 from Table 1. Also, it was assumed that $N=6$.

In the next division of this sub-section, a specific example of the feasible workspace analyses will be given along with the simulation experiments used for comparison and validation of the CPR-WWA procedure.

\subsubsection{Example 1: The analysis of the feasible workspace for: $\psi=0[\mathrm{rad}], \theta=0[\mathrm{rad}]$ and $\varphi=0[\mathrm{rad}]$}

Now a comparative analysis of the feasible workspace acquired by the CPR-WWA procedure and the corresponding simulation experiments will be given. The simulation experiments were defined as straight lines which confirm the feasible workspace 
achieved by the defined procedure. It was assumed that $\psi=0[\mathrm{rad}], \theta=0[\mathrm{rad}]$ and $\varphi=0$ $[\mathrm{rad}]$. The feasible workspace is shown in Fig. 4.

Fig. 4a) shows the result achieved by the CPR-WWA procedure and this figure was generated directly from MATLAB. Fig. $4 \mathrm{~b}$ ) presents the result acquired by the simulation experiments and this figure was generated in CorelDRAW. The simulation experiments were achieved by creating straight lines in the $x$ and $y$ directions at $N=6$ levels in the $z$ direction. By comparing these two figures, their matching can be noticed. This is a confirmation that the defined procedure CPR-WWA gives good results. From these figures, it can be seen that for $\psi=0[\mathrm{rad}], \theta=0[\mathrm{rad}]$ and $\varphi=0[\mathrm{rad}]$, and the chosen Actuator 1 from Table 1 the feasible workspace is 100[\%] in comparison with the geometric workspace from Fig. 3.

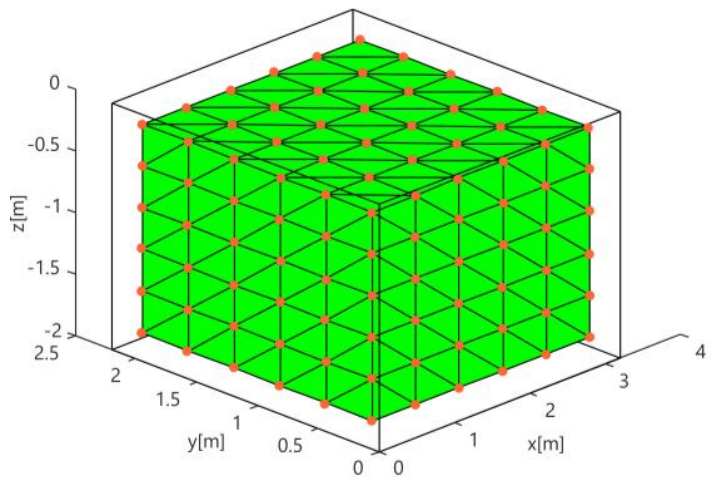

a)

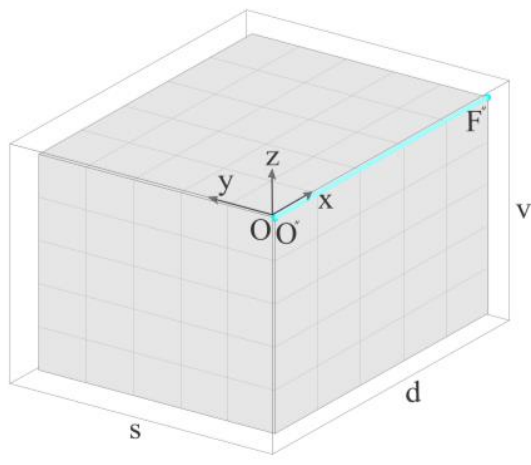

b)

Fig. 4 Feasible workspace of the CPR-8 system generated by a) the defined procedure CPR-WWA and b) simulation experiments for: $\psi=0[\mathrm{rad}], \theta=0[\mathrm{rad}]$ and $\varphi=0[\mathrm{rad}]$

\subsubsection{Example 2: The analysis of the feasible workspace for: $\psi=0,5[\mathrm{rad}], \theta=0,5[\mathrm{rad}]$ and $\varphi=0,5[\mathrm{rad}]$}

This example was made under identical conditions and for the same parameters as Example 1 from division 3.1.1, with the only difference in carrier's orientation, which is now $\psi=0,5[\mathrm{rad}], \theta=0,5[\mathrm{rad}]$ and $\varphi=0,5[\mathrm{rad}]$. During the analysis of the feasible workspace, the orientation is kept constant, i.e. $\dot{\psi}=\dot{\theta}=\dot{\varphi}=0$.

The results achieved with the CPR-WWA procedure are given in Fig. 5a), while Fig. $5 b)$ shows the results achieved with the simulation experiments. From Fig. 5 it can be seen that with the chosen orientation of the carrier $\psi=0,5[\mathrm{rad}], \theta=0,5[\mathrm{rad}]$ and $\varphi=0,5$ [rad], the feasible workspace is smaller than one achieved in Example 1 from division 3.1.1, see Fig. 4. The feasible workspace calculated by the defined procedure CPR-WWA in this case is 84.7[\%] in comparison with the geometric workspace of the CPR-8 system's load carrier shown in Fig. 3. The simulation experiments confirmed the results achieved with the CPR-WWA procedure, as can be seen from the similarity between Figs. 5a) and 5b). 

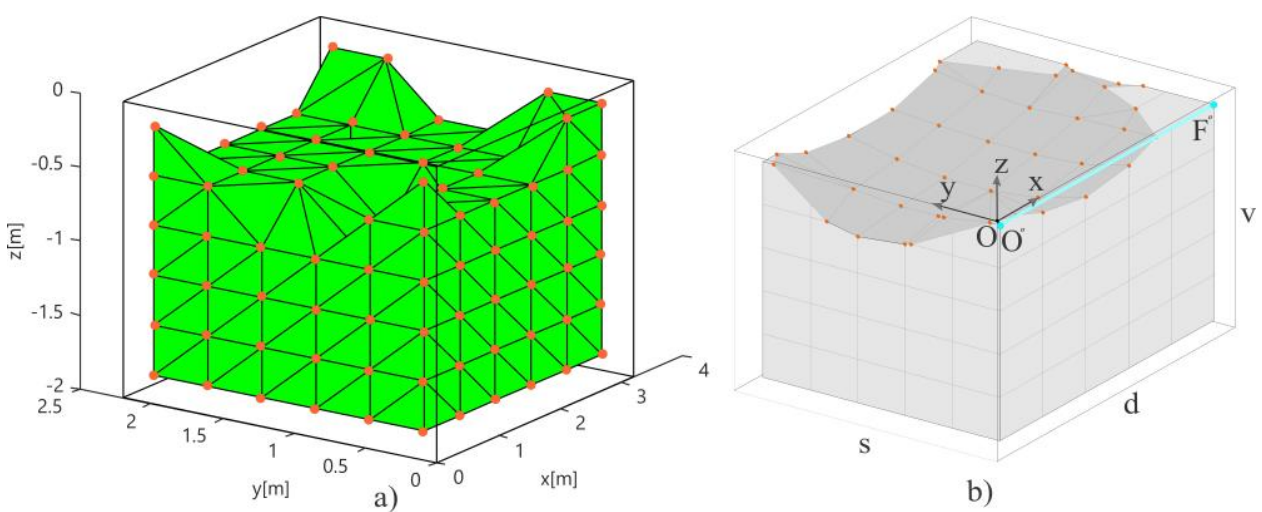

b)

Fig. 5 Feasible workspace of the CPR-8 system generated by a) the defined procedure CPRWWA and b) simulation experiments for: $\psi=0,5[\mathrm{rad}], \theta=0,5[\mathrm{rad}]$ and $\varphi=0,5[\mathrm{rad}]$

\subsubsection{The simulation results}

The purpose of this division is twofold:

I) to show how the results form Figs. 4b) and 5b) were obtained, and

II) to compare these results.

The results of the simulation experiments of only one straight line from the geometric workspace will be shown. The chosen line connects the points $O$ " and $F$ ". This motion is coloured in light blue in Figs. 4b) and 5b).

Comparative results of the mentioned trajectories are shown in Fig. 6. It should be emphasized that the simulation experiments were made under the same conditions and for the same parameters of the CPR-8 system with the only difference in carrier's orientation. Example a) from Fig. 6 relates to the motion when Euler angles are $\psi=0[\mathrm{rad}], \theta=0$ $[\mathrm{rad}]$ and $\varphi=0[\mathrm{rad}]$, see Fig. 4b), while example b) from Fig. 6 shows the results for trajectory when $\psi=0,5[\mathrm{rad}], \theta=0,5[\mathrm{rad}]$ and $\varphi=0,5[\mathrm{rad}]$, see Fig. 5b).

Each example shows the changes of: angular velocity behind the gearbox, load torque behind the gearbox, and control signal of the motor for all eight actuators. In example a), it can be seen that all the variables satisfy conditions defined by eqs. (30), (32), and (34).

This means that this trajectory belongs to the feasible workspace of the CPR- 8 system. This is also presented in Fig. 4b). Unlike example a) from Fig. 6, it can be seen that not all of the variables shown in example b) from Fig. 6 satisfy these conditions. It can be seen that angular velocity satisfies the condition from eq. (30) and control signals satisfy the condition from eq. (34), while load torques $M_{1}, M_{3}$ and $M_{8}$ do not satisfy the condition given by eq. (32). This means that the chosen actuator does not satisfy the requirements which are needed for the trajectory to be executed. So, this trajectory only partially belongs to the CPR-8 system's feasible workspace shown in Fig. 5b). 

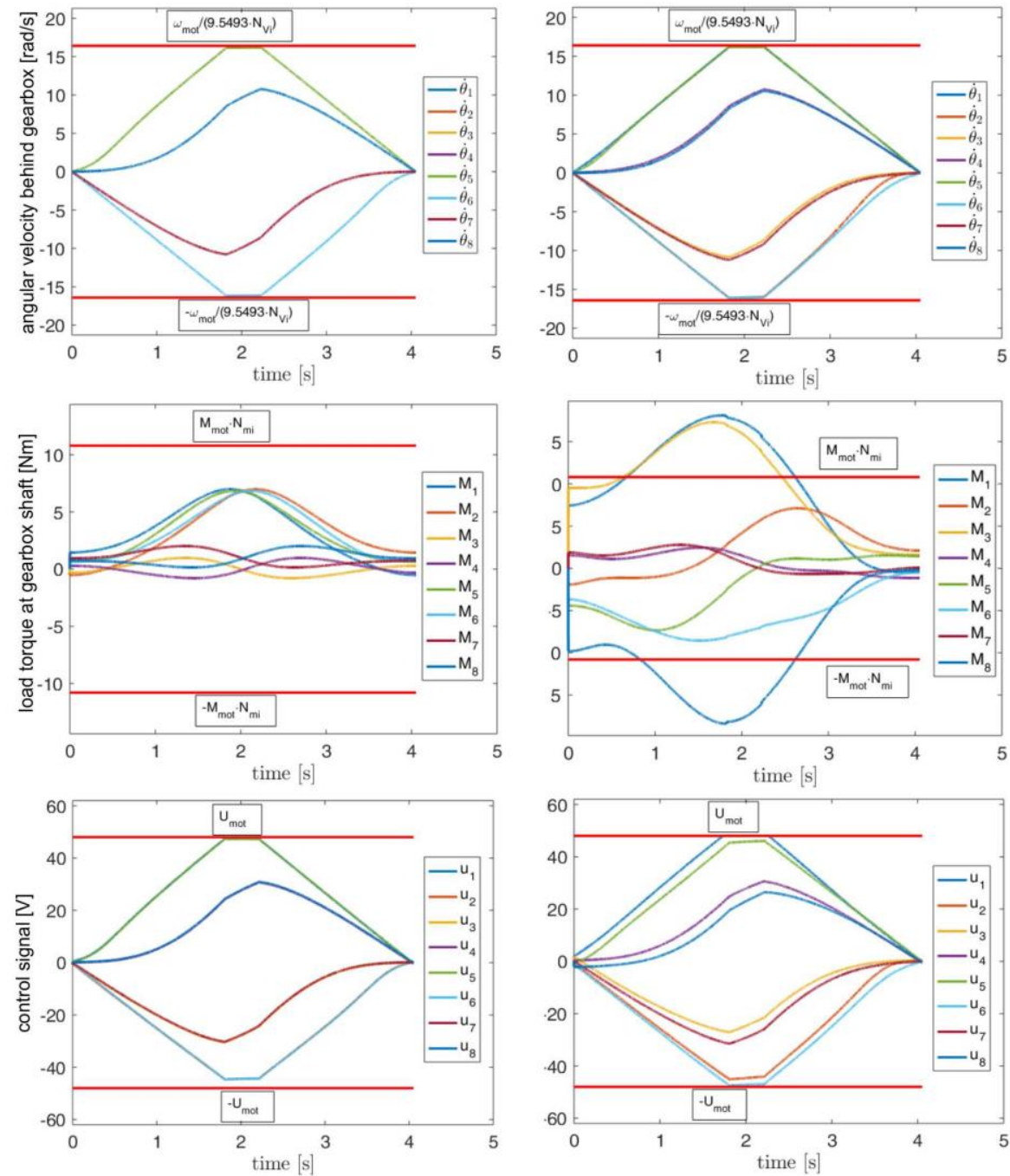

a)

b)

Fig. 6 The simulation results of trajectory $O$ ”- $F$ ” for the following Euler angles:

a) $\psi=0[\mathrm{rad}], \theta=0[\mathrm{rad}]$ and $\varphi=0[\mathrm{rad}]$ and b) $\psi=0,5[\mathrm{rad}], \theta=0,5[\mathrm{rad}]$ and $\varphi=0,5[\mathrm{rad}]$

The feasible workspaces given in Figs. 4b) and 5b) were achieved in exactly the same fashion - by execution of the number of straight lines (trajectories) at different levels in the $x, y, z$ coordinate system. In this way, it was obtained that the feasible workspace presented in Fig. 4b) when $\psi=0[\mathrm{rad}], \theta=0[\mathrm{rad}]$ and $\varphi=0[\mathrm{rad}]$ is identical to the geometric workspace shown in Fig. 3. E.g. from Fig. 5b) where $\psi=0,5[\mathrm{rad}]$, $\theta=0,5[\mathrm{rad}]$ and $\varphi=0,5[\mathrm{rad}]$, it can be seen that the feasible workspace is much smaller in comparison with the one from Fig. 3. 
Also, it can be generally concluded (for Figs. 4 and 5) that the simulation experiments confirm the validity of the novel procedure CPR-WWA used for performing the analysis and synthesis of the feasible workspace of the CPR-8 system.

In the next Section, a novel methodology for choosing CPR-8 system's actuator will be defined based on user's requirements, available actuator data base, and the defined procedure CPR-WWA.

\section{THE Methodology FOR CHOOSING CPR-8 SYSTEM'S ACTUATOR}

The Novel procedure CPR-WWA for the analysis and synthesis of the feasible workspace of the CPR-8 system which includes the kinematics and dynamics of the system and mathematical model of the actuator was presented in Section 3. This procedure opened a space for new research to define a novel methodology for choosing the CPR-8 system's actuators.

The main contribution of this paper is development of a novel methodology, named CPR-ACM (CPR-A $\underline{A}$ ctuator $\underline{\text { Choice }}$ Methodology), which is intended to interconnect the engineering knowledge from this area and the theoretical analysis presented here. Because the procedure CPR-WWA used for the analysis and synthesis of workspace was created by using eqs. (19)-(21), which include the complete kinematics and dynamics of the CPR-8 system along with actuator's dynamics, a novel methodology CPR-ACM for a systematic analysis of usability of several actuators can be generated. Catalogue parameters of the actuators are kept in a data base. CPR-ACM uses its logic and selects the corresponding actuator(s) from the data base, according to user's requirements supported by the knowledge and imagination of the designer. In the course of making choice of the actuator, the CPR-WWA procedure from Section 3 is used for calculation of the feasible workspace of the CPR- 8 system for each chosen actuator. During the development of this methodology, it was evident that the complexity of the CPR-8 system, its actuators, and other parameters was considerable. All these parameters are mutually strongly coupled. Development of the CPR-ACM methodology is important because it is applicable not only to the CPR-8 but to any other robotic system.

Flow chart of the methodology CPR-ACM is presented in Fig. 7.

At the beginning, parameters of the CPR-8 system are defined. These parameters are defined together with the end-user in accordance with the design requirements. All the parameters are kept the same during the analysis of each of the actuators. Based on the parameters of the system and the requirements of the user, the desired percentage of the feasible workspace $x[\%]$ relative to the geometric workspace of the CPR-8 system is defined.

In general, the data base contains $M$ different actuators. By using each of these actuators, the feasible workspace of the CPR-8 system will be calculated. Upon completion of this sub-program, the obtained feasible workspaces will be compared. Counter $i_{a}$ is initialized at the beginning, as shown in Fig. 7. During each passing through the loop, the parameters of the $i_{a}$-th actuator are loaded and the CPR-WWA procedure from Section 3 is used for performing the analysis and synthesis of the current feasible workspace of the CPR-8 system. The Variable $x\left(i_{a}\right)[\%]$ represents the percentage of the feasible workspace in comparison with the geometrical workspace of the CPR-8 system. For each passing through the loop, the feasible workspace percentage is memorized and connected with the type of the current actuator. This process is repeated for all $M$ actuators. 


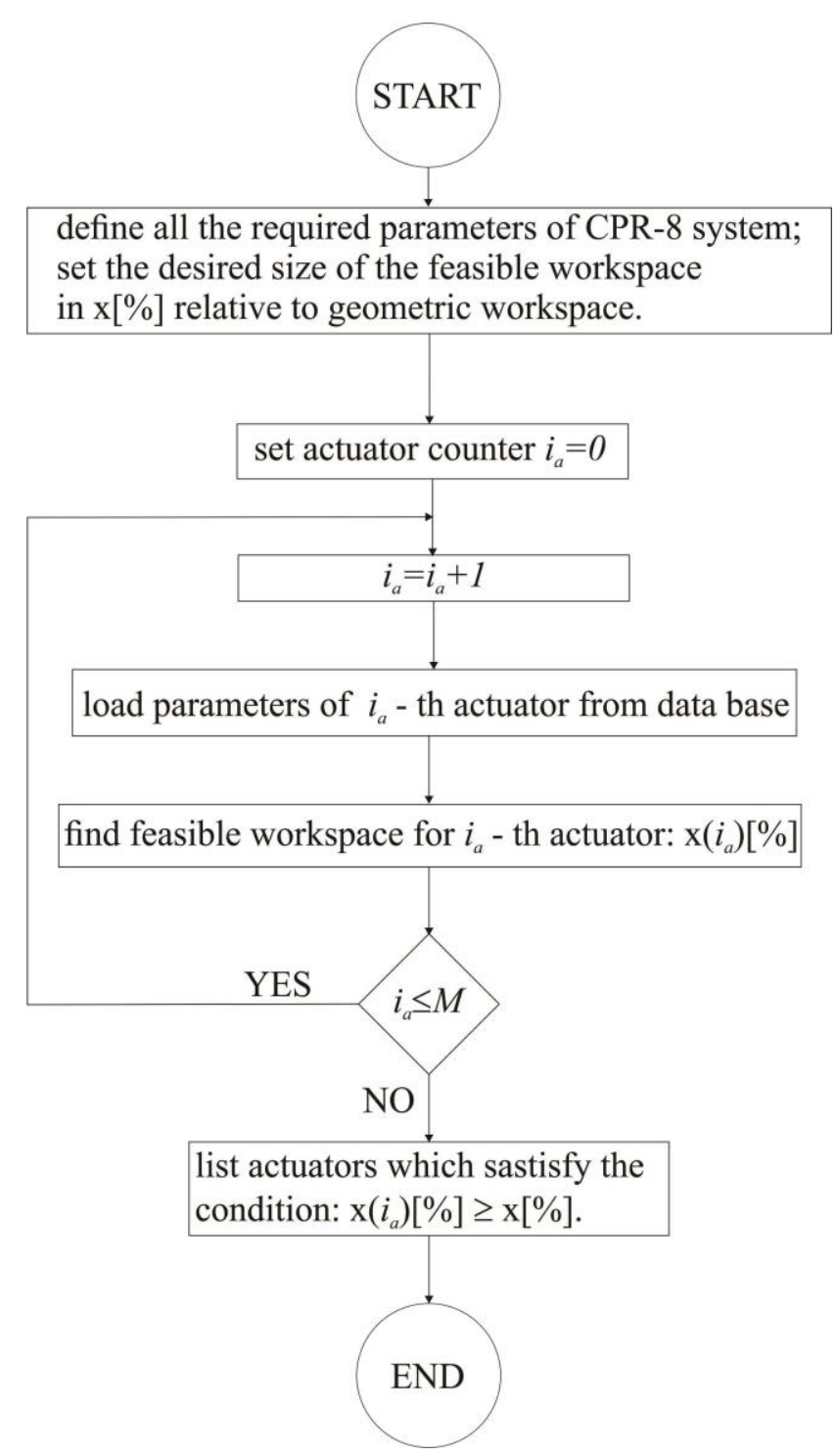

Fig. 7 Flow chart of the CPR-ACM methodology

When $i_{a}=M$, this process is ended and the program logic generates the list of all actuators which satisfy the condition: $x\left(i_{a}\right)[\%]>x[\%]$. In this fashion, only the actuators which satisfy user's and designer's requirements are listed. 


\section{PROGRAM PACKAGE PPACM - SIMULATION EXPERIMENTS}

Based on the methodology CPR-ACM which comprises the procedure CPR-WWA as its sub-program, a program package named PPACM (Program Package $\underline{\text { Actuator }}$ Choice Methodology) was developed. PPACM is a complex unit which contains a number of other sub-programs. Only the most important sub-programs are listed here:

1. kinematic model of the CPR-8 system,

2. dynamic model of the CPR-8 system,

3. procedure CPR-WWA used for performing the analysis and synthesis of the feasible workspace of the CPR-8 system, and

4. methodology CPR-ACM.

PPACM was used for generation of the results and validation of the novel methodology CPR-ACM. The results are given through the case study presented in the continuation of this text.

\subsection{Case study: Example of CPR-ACM methodology and PPACM application for a CPR-8 system}

In order to facilitate understanding of the procedure CPR-WWA, methodology CPR$\mathrm{ACM}$, and generally program package PPACM, one example of choosing the actuator of a CPR-8 system will be presented in this sub-section.

In this example, the same parameters of the CPR-8 system used in division 3.1.1 of Section 3 will be used. Catalogue parameters of the potential actuators are given in Table 1. It can be seen that the number of actuators is $M=5$. It is assumed that the user requires a feasible workspace of at least $x[\%]=90[\%]$ in comparison with the geometric workspace shown in Fig. 3. The following results were generated by the program package PPACM. The feasible workspace achieved with Actuator 1 was presented in Fig. 4a) and it can be seen that it is $x(1)[\%]=100[\%]$. The feasible workspaces of the CPR-8 system achieved with Actuators 2, 3, 4 and 5 are shown in Figs. 8a), 8b), 8c) and 8d), respectively.

These figures show the reductions of the feasible workspace, the percentage is shown in Table 2. In order to facilitate understanding, these results are also shown in Fig. 9. From the given results, it can be seen that only Actuators 1 and 2 satisfy the condition set by the user, $x\left(i_{a}\right)[\%] \geq 90[\%]$, marked by the grey color in Table 2 and shown in Fig. 9 .

It can be seen that Actuators 3 and 4 do not satisfy the requirements set by the user and designer. But these two actuators are interesting from another perspective. It can be noticed that Actuator 3 has output power $P_{m o t}(3)=50[\mathrm{~W}]$, while Actuator 4 has output power $P_{\text {mot }}(4)=20[\mathrm{~W}]$. Regardless of this fact, Actuator 3 has percentage of the feasible workspace $x(3)[\%]=85.19[\%]$, while Actuator 4 has this percentage as $x(4)[\%]=87.04[\%]$ in comparison with the geometric workspace of the CPR-8 system. Compare Figs. 8b) and 8c) and see Fig. 9 as well. This may seem illogical to be presented in this paper. However, this result is presented since it is very interesting, because it was not achieved by accident. Through the research related to the development of methodology CPRACM, a much larger number of actuators were analyzed. These analyses could not be shown in this paper. It was noticed that several of these "illogical results" appeared repeatedly.

This phenomenon is analyzed in more detail, because it appeared in a number of different cases. It can be concluded that output power of the actuator, which is given in 
the catalogue, is not a relevant indicator for making actuator choice during the CPR system's construction. Here, it is evident that other parameters of the actuators given in Table 1, and their mutual influence on dynamics of the actuators and CPR system, have a significant role in generation of the system's feasible workspace. This opens a space for new research, not only in the field of Robotics, but much wider. Motor manufacturers would probably be especially motivated for supporting the research in this field.

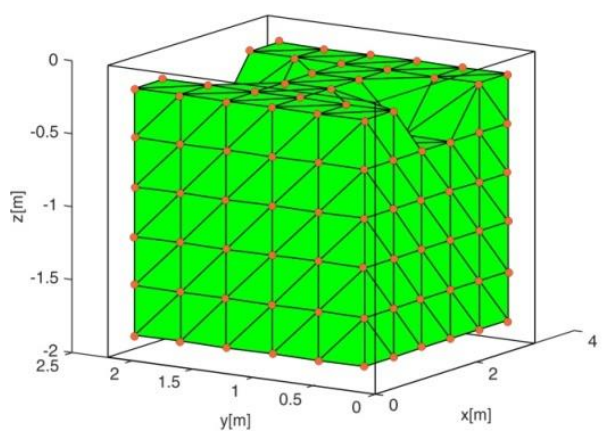

a)

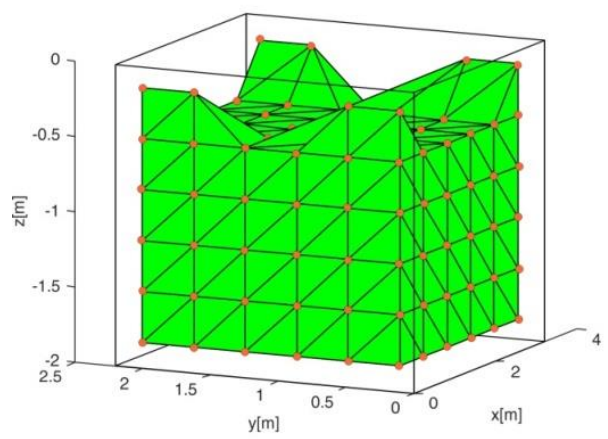

c)

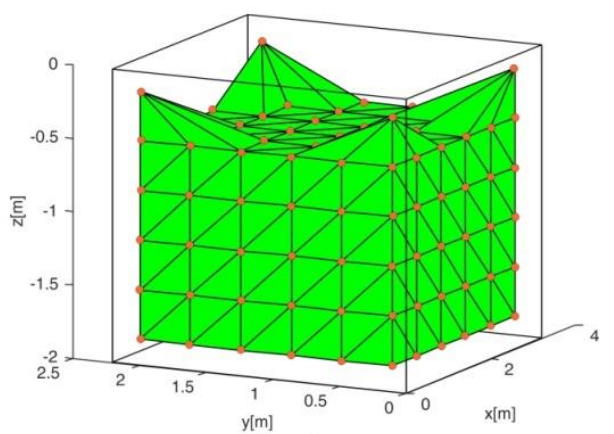

b)

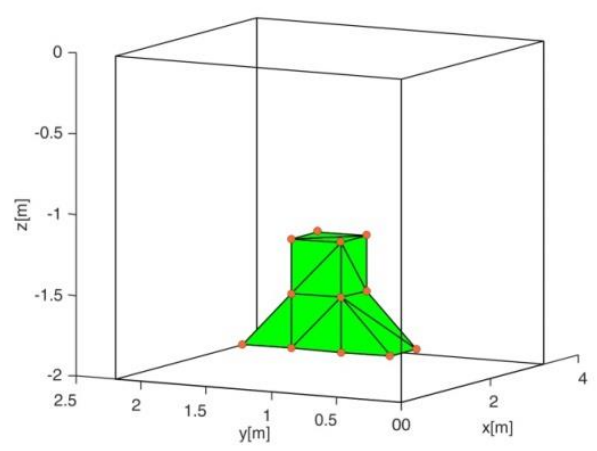

Fig. 8 The feasible workspaces achieved with Actuator: a) 2, b) 3, c) 4, and d) 5 .

Table 2 The results achieved by using the CPR-ACM methodology

\begin{tabular}{|c|c|c|c|c|c|}
\hline Actuator & $1\left(i_{a}=1\right)$ & $2\left(i_{a}=2\right)$ & $3\left(i_{a}=3\right)$ & $4\left(i_{a}=4\right)$ & $5\left(i_{a}=5\right)$ \\
\hline $\begin{array}{l}\text { Acquired feasible workspace } \\
x\left(i_{a}\right)[\%] \text { for } \\
\psi=0[\mathrm{rad}], \theta=0[\mathrm{rad}] \text { and } \varphi=0[\mathrm{rad}]\end{array}$ & 100 & 96.3 & 85.19 & 87.04 & 7.41 \\
\hline Presented in & Fig. 4a) & Fig. 8a) & Fig. 8b) & Fig. 8c) & Fig. 8d) \\
\hline
\end{tabular}

The CPR-ACM methodology for choosing an actuator is based on the mathematical model of the CPR-8 system. Good formulation of the mathematical model and the phenomena which characterize the CPR-8 system is a pre-requisite for achieving a realistic feasible workspace. By relying on this methodology, a designer of the CPR-8 system has a valuable help during the process of construction of the system. 
The developed CPR-ACM methodology was tested on the CPR-8 system. With slight modifications it can be tested on any robotic configuration. This methodology could, e.g., be tested on the robotic system presented in [20] or on ROBED03 robot which was developed at Robotics laboratory at Mihailo Pupin Institute, Belgrade in 2003.

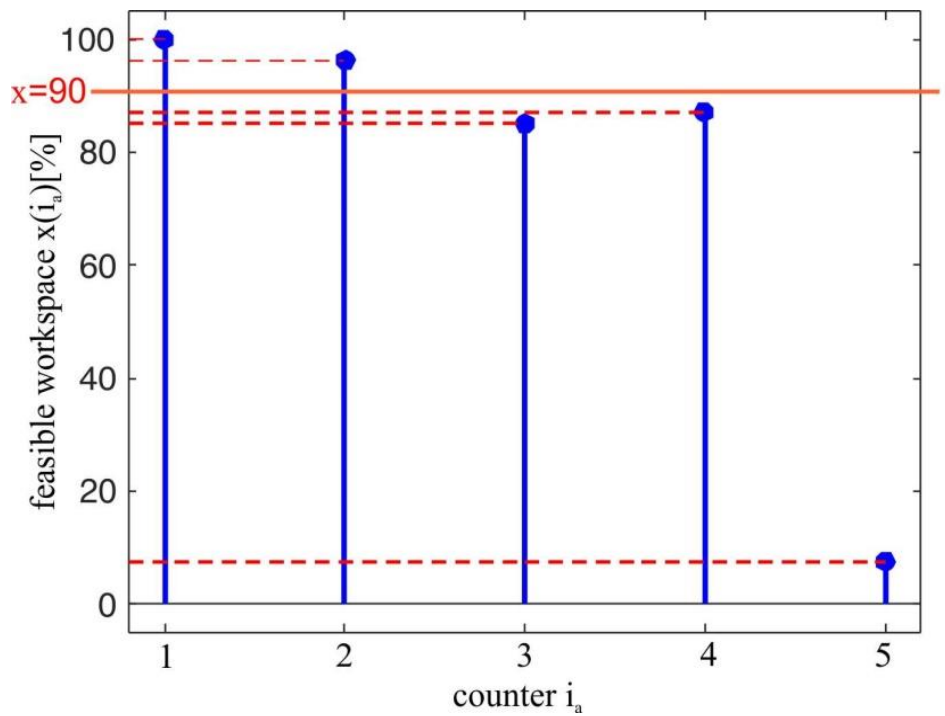

Fig. 9 A comparative presentations of the feasible workspaces achieved by different actuators

\section{CONCLUSION}

The main contribution of this work is the development of a novel methodology for choosing an actuator for the CPR-8 system, named CPR-ACM. This methodology implies the formulation and application of a data base which contains catalogue parameters of the actuators available at the market. Both, users and designers define together the parameters and desired feasible workspace of the CPR- 8 system being designed. The methodology is illustrated by a logic flow chart. It calculates the feasible workspaces for all available actuators from the data base and by a comparative analysis it identifies for the user and designer the possible usefulness of every available actuator. For calculation of feasible workspace, this methodology uses a novel procedure CPRWWA for analysis and synthesis of the feasible workspace of the CPR-8 system which was developed in this paper as well. This procedure is based on a complete kinematic and dynamic model of the CPR-8 system, as well as on the mathematical model of the actuator. Inclusion of actuator's mathematical model in the procedure CPR-WWA presents a novelty in comparison with available literature. Complexity of the procedure is high, because it involves mainly the parameters of the system which are mutually strongly coupled. The CPR-WWA procedure was defined and its validity was tested through a set of simulation experiments. Overlapping between the results achieved with application of the procedure and the results achieved from the simulation experiments is observed. In this way, a confirmation was achieved that the CPR-WWA procedure gives 
useful results. Through this research it is recognized that all actuator parameters affect the size of the feasible workspace of the CPR-8 system. Combination of these parameters is very important. It should be emphasized, that the actuator should not be chosen based only on one parameter, because all the other parameters, since they are strongly coupled, can equally strongly influence the response dynamics of the system.

A novel program package PPACM was defined. PPACM contains the methodology CPR-ACM and procedure CPR-WWA and makes a sub-program of this methodology. The program package is user friendly and offers the user all the benefits of the designed procedure CPR-WWA and methodology CPR-ACM.

The procedure CPR-WWA and methodology CPR-ACM are developed and tested on a CPR-8 system. With slight modifications, it is possible to use them with different complex configuration, e.g. industrial robotic configuration or other cable robot systems.

\section{REFERENCES}

[1] J. Albus, R. Bostelman, N. Dagalakis, "The NIST robocrane," J. Robot. Syst. 10(5), pp. 709-724, 1993.

[2] S. Kawamura, W.S. Tanaka, Pandian, "Development of an ultrahigh speed robot falcon using wire drive system," In: IEEE International Conference on Robotics and Automation, pp. 1764-1850, 1995.

[3] M. Filipovic, A. Djuric and Lj. Kevac, "The rigid S-type cable-suspended parallel robot design, modelling and analysis," ROBOTICA, 34 (9), pp.1948-1960, 2016.

[4] M. Filipovic, A. Djuric and Lj Kevac, "The significance of adopted Lagrange principle of virtual work used for modeling aerial robots," Applied Mathematical Modelling, 39(7), pp. 1804-1822, 2015.

[5] M. Filipovic, A. Djuric, "Cable-suspended Parallel Robot type CPR-D," Journal of Theoretical and Applied Mechanics, J THEOR APP MECH-POL, Warsaw, Poland, 54, 2, pp. 645-657, 2016.

[6] J. Pusey, A. Fattah, S. Agrawal, E. Messina, "Design and workspace analysis of a 6-6 cable-suspended parallel robot," Mechanism and Machine Theory, 39, pp. 761-778, 2004.

[7] C. B. Pham, S. H. Yeo, G. Yang, M. S. Kurbanhusen, I-M. Chen, "Force-closure workspace analysis of cable-driven parallel mechanisms," Mechanism and Machine Theory, 41, pp. 53-69, 2006.

[8] C. Tavolieri, J-P Merlet, M. Ceccarelli, "A Workspace Analysis of a Overconstrained Cable-Based Parallel Manipulator by Using Interval Analysis," 3rd International Symposium on Multibody Systems and Mechatronics, MUSME 2008, San Juan - Argentine, pp. 1-13, 8-12 April 2008.

[9] X. Diao, O. MaForce-closure analysis of 6-DOF cable manipulators with seven or more cables," ROBOTICA, 27, pp. 209-215, 2009.

[10] C. B. Phama, S. H. Yeob, G. Yangc, I-M. Chenb, "Workspace analysis of fully restrained cable-driven manipulators," Robotics and Autonomous Systems, 57, 2009.

[11] W. M. Nunes, J. F. Ribeiro, J. C. M. Carvalho, R. S. Gonçalves, "Kinematics Modeling And Workspace Analysis Of A Cable-Based Parallel Manipulator For Houlder Rehabilitation," ABCM Symposium Series in Mechatronics - Vol. 5, Section VII - Robotics (2011), Natal, RN, Brazil, pp. 988 - 998, 2011.

[12] Q. Duan, V. Vashista, S. K. Agrawal, "Effect on wrench-feasible workspace of cable-driven parallel robots by adding springs," Mechanism and Machine Theory, 86, pp. 201-210, 2015.

[13] X. Wang, Y. Hu and Q. Lin, "Workspace analysis and verification of cable-driven parallel mechanism for wind tunnel test," Proc IMechE Part G: J Aerospace Engineering 0(0), pp. 1-10, 2016.

[14] J.M. Heo, S.H. Choi, K.S. Park, "Workspace analysis of a 6DOF cable driven parallel robot considering pulley bearing friction under ultrahigh acceleration," Microsystem Technologies, 23(7), pp. 2615-2627, 2017.

[15] L. Gagliardini, S. Caro, M. Gouttefarde, "Dimensioning Of Cable-Driven Parallel Robot Actuators, Gearboxes And Winches According To The Twist Feasible Workspace," 2015 IEEE International Conference On Automation Science And Engineering (Case), Gothenburg, Sweden, pp. 99-105, 24-28 August 2015.

[16] W. Kraus, A. Pott, "Scenario-Based Dimensioning of the Actuator of Parallel Cable-Driven Robots," in: F. Viadero and M. Ceccarelli (eds.), New Trends in Mechanism and Machine Science, Mechanisms and Machine Science book series, 7, pp. 131-139, August 2012. 
[17] M. Filipovic, A. Djuric, Lj. Kevac, "The mathematical model of aerial robot in purpose increasing of its autonomy," 20th Telecommunications Forum, TELFOR 2012, Belgrade, Serbia, ISBN 978-4673-29842/12, pp. 1575-1578, 20-22 November 2012.

[18] M. Filipovic, Lj. Kevac, "A new Winch Construction for Smooth Cable Winding/Unwinding," FACTA UNIVERSITATIS, Series: Mechanical Engineering, University of Niš, Vol. 15, No 3, pp. 367 - 381, 2017.

[19] Lj. Kevac, M. Filipovic, "Mathematical Model of Cable Winding/Unwinding System," Journal of Mechanics, J MECH, Cambridge University press, DOI: 10.1017/jmech.2017.59, Published online: 18 August 2017.

[20] A. Djuric, M. Filipovic, W. Chen, "Visualization of the three critical spaces related to the 6-DOF machinery," 4th International Congress of Serbian Society of Mechanics, Vrnjacka Banja, Serbia, pp. 915-920, 4-7 June 2013. 